\title{
Parent Attitudes Towards the Integration of Digital Learning Games as an Alternative to Traditional Homework
}

Meital Amzalag, Holon Institute of Technology, Israel

\begin{abstract}
The COVID-19 pandemic caused children to distance learn at home, but with technical and pedagogic difficulties. Digital learning games offer effective tools for pedagogic difficulties, such as active and relevant learning. Using mixed-methods research, this study examined 1) parents' perceptions about digital learning games and 21st century skills and 2) parents' attitudes towards digital learning games instead of traditional homework. The findings are based on both qualitative (in-depth interviews) and quantitative (online survey) data. The results of the study revealed that parents do not object to replacing traditional homework with digital learning games. They saw digital learning games as relevant for their children's digital lives and acknowledged their potential to reduce arguments over homework. Therefore, digital learning games should be employed in school and as an alternative for traditional homework, both in routine and crisis, such as the COVID-19 pandemic.
\end{abstract}

\section{KEYWORDS}

21st Century Skills, Digital Learning Games (DLG), Homework, Parents' Attitudes

\section{INTRODUCTION}

In the present era, old knowledge becomes outdated rapidly and new knowledge is rapidly produced. This vast amount of knowledge and the labor market's characteristics rely heavily on different uses of technology that facilitate the creation of new knowledge and expansion of the human's knowledge capacity and abilities (Binkley et al., 2010).

To supply the state with suitable manpower adapted to the developments and skills such as creativity, innovation, critical thinking, problem-solving, collaborations (Soulé \& Warrick, 2015), known as $21^{\text {st }}$ century skills (Van Laar et al., 2017), students should be equipped from an early age for the current increasing complexity of life and the work environment (Donovan et al., 2014).

In recent years, there has been growing interest and research concerning the way in which technology can advance critical thinking and problem-solving for students in elementary, junior high and senior high schools (Mtshali, 2020). Technology enables life-long learning throughout formal and informal learning and activities are offered in mixed (online and face-to-face) and online learning (Donovan et al., 2014; Romero, 2015). One of these activities is gamification and digital learning games.

Gamification refers to the use of game elements for non-game activities (Kiryakova et al., 2014; Schöbel et al., 2020). Scholars argue that using game mechanisms, in a context different from the game, increases learner involvement and improves motivation (Kingsley \& Grabner-Hagen, 2015; Kiryakova et al., 2014). In addition, Research literature indicates the varied advantages of the inclusion

\section{DOI: 10.4018/IJICTE.20210701.oa10}

\footnotetext{
This article, published as an Open Access article on April 23rd, 2021 in the gold Open Access journal, the International Journal of Information and Communication Technology Education (converted to gold Open Access January 1st, 2021), is distributed under the terms of the Creative Commons Attribution License (http://creativecommons.org/licenses/by/4.0/) which permits unrestricted use, distribution, and production in any medium, provided the author of the original work and original publication source are properly credited.
} 
of learning games in learning process such as pleasure, satisfaction, challenge, involvement in the learning, flow, improved academic achievements, creativity, active learning and social opportunities (Hamari et al., 2016; Hung et al., 2015; Romero et al., 2015; Wang, 2019).

As a result of the recent pervasion of technology in our lives, computer-based learning games have caught the attention of educators. These games have been designed and developed to be enjoyable, challenging and exciting but also adapted to different learning disciplines according to learning programs (Buckley \& Doyle 2016; Huang et al., 2018; Yildirim, 2017).

Despite the advantages of digital learning games, schools are very slow in adopting these games as part of their learning programs partly because of the resistance of students' parents (Piller \& Roberts-Woychesi, 2015). The research examined whether there was an alteration in the students' parents' attitudes towards the use of digital learning games in school studies as a result of technological development. The research also aimed to investigate parents' attitudes towards the acquisition of skills through digital learning games and through digital learning games that replace traditional homework.

The research was conducted in Israel, which is known as the "start-up nation", since it is the home for more start-ups per population than any other world nation (Fraiberg, 2017). These startup companies create practical technology in a very wide range of areas (Israel's Central Bureau of Statistics, 2019), which has a significant influence on Israel's population (Israeli Internet Association, 2015).

\section{LITERATURE REVIEW}

Individuals and organizations are required to adopt life-long learning strategies to remain competitive in the global environment (Binkley et al., 2010; Romero, 2015). Twenty-first century skills include creativity, innovation, critical thinking, problem-solving, collaborations, information literacy, knowledge and telecommunications, effective communication and adaptation, which are the hallmarks of competitive and growing industries that require skilled creative and dynamic manpower (Binkley et al., 2010; Obschonka et al., 2017; Romero, 2015).

Education systems need to imprint these skills in their learners from an early age, to prepare them to act as participating adults in future societies, in a world that does not yet exist and is not clearly defined (Barak, 2017). However, $21^{\text {st }}$ century skills are insufficient without the development of other cognitive and social-affective skills that enable the individual to perform tasks and solve problems in digital environments (Binkley et al., 2010; Obschonka et al., 2017). Digital environments enable learners to access immense sources of information and to create a learner community in a relatively easy manner. They also empower the learners and allow them to own their own learning and even to learn in collaboration with other (Choy et al., 2016).

Digital environments may be divided into four parts: 1) Digital teaching materials such as e-books, content presented in digital ways and the like.; 2) Digital tools such as desktop and laptop computers, tablets, smart phones etc.; 3) Digital delivery - delivering learners' learning activity via the internet; 4) Autonomous learning - digital learning by the learners themselves (Lin et al., 2017).

Digital environments can promote active learning, which is one way to transmit $21^{\text {st }}$ century skills and to create effective high-quality learning for learners. This learning approach focuses on the learners, it is based on problem-solving and provides a positive and meaningful life-long learning experience. It combines activities that help to develop the learner's skills, and increases learners' involvement in their studies (Romero et al., 2015; Qian \& Clark, 2016), promoting their commitment to learning tasks and enabling learners to cope with new challenges and adapt to knowledge technologies. One of the tools identified as potentially promoting and supporting active learning and $21^{\text {st }}$ century skills is gaming (Romero et al., 2015), which promote learning skills, information and media and technology skills (Ibharim et al., 2019). 


\section{Gaming}

Different gaming activities are often mistakenly defined as games even though the correct term is gamification. Gamification is the use of game elements in non-entertainment-based contexts, or non-game activities (Palomino et al., 2019; Schöbel et al., 2020). Gaming activity creates a sense of fun and enjoyment, but it is only defined as a game if it answers certain criteria for example: consensual participation (Kramer, 2000), the challenge is appropriate for the participant, with a clear goal (Hamari et al., 2016; Kramer, 2000; Rieber, 1996) there is clear and consistent feedback (Kramer, 2000) and the sense of time is not felt during the activity (hours pass without the passage of time being noticed) etc. (Rieber, 1996).

The first stages of the game usually begin with easy tasks and continue to more difficult tasks, according to the development of the players' skills (Hamari et al., 2016). In this way, the game designers are inflicting players to play over a period of time, and the players improve their skills and construct knowledge (Hamari et al., 2016; Perez-Liebana et al., 2016). This is a cyclic process; insofar as the player's skills improve, the challenge's level increases suitability. To solve this new level, the player must continue to improve his skills. The game mechanism introduces the player new challenges, which cause increase and improve abilities gradually (Hamari et al., 2016; Sweetser \& Wyeth, 2005). Today, it is easier to enter this cyclic process because many digital games allow players to adapt the level of challenge when their skills improve during the game (Denisova \& Cairns, 2019).

Game-based learning is distinguished from entertainment-oriented games. Although enjoyable, these games are primarily designed for different purposes whereas, entertainment-oriented games are intended solely for entertainment and leisure time activity (Fleming et al., 2017; Hamari et al., 2016; $\mathrm{Xu}$, Buhalis \& Weber, 2017). In contrast, learning games aim mainly to educate or train, leveraging the characteristics and principles of entertainment-oriented games to foster internal motivation, expose learners to different specific problem scenarios, and engage students in learning (Gao et al., 2020; Gentile et al., 2019)

Learning games have captured a larger space as a tool for the performance of instructions due to recent technological developments, known as Information and Communication Technologies (ICT). These technologies enable the creation of virtual, realistic simulated environments, in which players can enter an adventure while it takes place, and exercise and acquire and improve knowledge, enhance thinking skills, learn problem-solving in an active and realistic environment, learn with friends and receive immediate feedback according to various pedagogic paradigms (Gentile et al., 2019; Iten \& Petko, 2016).

Research literature indicates various advantages of the introduction of learning games in learning, process which are related with including enjoyment, satisfaction, challenge, involvement in learning, flow, increased academic achievements, creativity, active learning, social opportunities etc. (Hamari et al., 2016; Hung et al., 2015; Romero et al., 2015; Sung et al., 2018). Several studies have indicated that games can provide an improved experience in comparison to other more prevalent teaching methods (Bellotti et al., 2010; Erhel \& Jamet, 2013; Guillen-Nieto \& Aleson-Carbonell, 2012; KickmeierRust \& Albert, 2012) and so they have potential to be used as learning tools (Carvalho et al., 2015).

With the evolution of technology, computer-based learning games have caught the attention of educators. They can be designed and developed so they are enjoyable, challenging and exciting without excluding learning and educational contents suitable for the subjects of lessons according to the curricula (Buckley \& Doyle, 2016; Huang et al., 2018; Yildirim, 2017). Thus, these games increase motivation and understanding among students from the present-day digital generation (Zahra et al., 2017). Motivation for success in the learning process merges with motivation for success and "winning" in the game (Figueroa-Flores, 2016).

Although games provide an improved experience in comparison to more prevalent teaching methods, schools are very slow to adopt digital learning games as part of their learning programs (Piller \& Roberts-Woychesi, 2015). There are three main reasons for this: lack of time (Sharp, 2012), 
parents' resistance to the inclusion of games at school (Piller \& Roberts-Woychesi, 2015) and lack of consensus concerning the positive influence of games-based learning on academic achievements (Emes, 1997; Qian \& Clark, 2016).

\section{Homework and Digital Learning Games}

Homework can be defined as an assignment given by the teacher, to be performed outside school hours (Katz et al., 2017). The most prevalent reason for homework is to provide the students with an opportunity to practice or revise learning materials presented in the classroom, and to enlarge learning in order to improve understanding and develop skills for independent work (Cooper et al., 2006; Moè et al., 2018). In contrast to assignments during schooltime, homework should be performed in the student's free time (Katz et al., 2009).

Many children do not like to prepare homework so they attain lower levels of pleasure and satisfaction and often have higher levels of anger, boredom, anxiety and frustration when they prepare homework in comparison to other school activities (Moè et al., 2018). Many students prepare homework because of a sense of duty, a desire to please others or to avoid punishment (Katz et al., 2017). Also, because homework preparation takes time during hours when children want to enjoy other informal activities (for example clubs, youth movements, meeting friends) or quality time with their families, many parents struggle to encourage their children to prepare homework and this becomes a factor for tension and stress for both parents and children (Bempechat, 2019; Burriss \& Snead, 2017; Katz et al., 2017). Additionally, research indicates that when homework is irrelevant to students' lives, they tend to invest in them less, and when homework is more relevant, parents relate to them as a pleasant task, and they contribute to children's motivation to prepare them (Burriss \& Snead, 2017).

Moreover, when gaming components are introduced into homework, such as a point system, the challenge is increased in order to make it more difficult to attain points and go on to the next level, positive feedback reinforces students' positive attitude and perception of themselves concerning their progress and growth. In a study by Goehle (2013) it was found that thanks to the use of gaming components in homework, $90 \%$ of the students fully prepared them.

\section{Parents' Roles in their Children's Education}

Parents have an essential role in their children's development in all life aspects, including education (Anero, 2019; Ceka \& Murati, 2016). They serve as role models and are responsible for providing information to help their children succeed (Anero, 2019). Parents may support their children through homework help, which helps create a daily learning routine (Ceka \& Murati, 2016). Moreorver, parents' involvement in their children's education yields positive effects on educational outcomes, their sense of belonging to the school community (Anero, 2019; Cai, 2003; Ceka \& Murati, 2016), and may even impact their children through adulthood, especially in the 21 st century (Anero, 2019).

\section{The Israeli Context}

The State of Israel is known as the "Start-up Nation", because it is the home to more start-up companies per population than any other world state (Fraiberg, 2017). These companies create practical technologies for a wide range of areas (Central Bureau of Statistics, 2019). This mean that technology is widely used by the Israeli population: as noted above, in $2018,83.7 \%$ of those over age 20 used the Internet in 2018 through a personal computer or Smartphone, 83\% of children aged 8-15 have a Smartphone and among those aged 15 the percentage using a Smartphone was 97\% (Israeli Internet Association, 2015).

Despite widespread discussion on $21^{\text {st }}$ century skills and the understanding that games contribute to learning, little research attention has been given to the influence of digital learning games on children's development of $21^{\text {st }}$ century skills (Qian \& Clark, 2016). The few studies of this issue found that computer games develop high order thinking skills and general $21^{\text {st }}$ century skills, but they did not mention which exact skills were examined (An \& Cao, 2017; Sardone \& Devlin-Scherer, 
2010). There are also few studies that deal with the provision of games in general and digital learning games in particular as an alternative for homework (Piller \& Roberts-Woychesi, 2015), and a few studies examine parents' attitudes towards the inclusion of digital learning games as an alternative for traditional homework (Bourgonjon et al., 2011). Parents' attitudes towards the introduction of digital learning games are very significant as are the rules concerning games in the home, they can influence the way in which their children relate to these games in the context of learning (Bourgonjon et al., 2011).

In light of the above review, the present study related to three main questions in consideration of the situation in Israel:

1. Which skills are expressed in digital learning games, according to parents' attitudes?

2. Is there a difference between parents' attitudes towards digital games, digital learning games and the use of digital learning games as an alternative for traditional homework?

3. Which factors influence parents' attitudes towards the use of digital learning games for homework?

\section{METHODOLOGY}

The research adopted a mixed methods methodology, combining both qualitative and quantitative data collection and analysis tools (Anderson \& Shattuck, 2012), which were collected from a questionnaire and semi-structed in-depth interviews.

\section{The Questionnaire}

A specially constructed four-part questionnaire: A) Questions relating to gender (of the parent), the class in which the child studied, the child's main use of the computer, parents' views on technology, the manner, and frequency of parents' involvement in the child's homework; B) Nine items examining parents' attitudes towards digital games (for example: "The digital game is a waste of time"); C) Seven items examining parents' attitudes towards digital learning games (for example: "Digital learning games encourage the learner to show responsibility and active involvement in the learning process"); D) Eight items examining parents' attitudes towards digital learning games as an alternative for traditional homework (for example: "Digital learning games, given as homework, allow learners to control the learning topics, thanks to immediate feedback"). Parents were asked to indicate their attitudes by marking their agreement with the questionnaire items on a Likert scale from 1-5, where $1=$ do not agree at all, and 5=agree to a large extent. The items were derived from two previous questionnaires (Blau \& Antonovsky 2009) with certain adaptations to the topic of the current study. The questionnaire was written on Google Forms and distributed online through WhatsApp, as a snowball sample, between February and April, 2019.

The data were analyzed with the help of SPSS software, including frequency tests, t-tests for independent samples and One-Way ANOVA tests. An R program was also used with a LAVAAN package (Rosseel, 2012) for the analysis of confirmative factors.

\section{In-Depth Semi-Structured Interviews}

The interviews were conducted after analyzing the questionnaire's findings to understand in depth the quantitative findings. On average, the interviews lasted approximately 30 minutes and related to parents' involvement in their children's lives (for example: "How is your involvement in your children's lives reflected?"), their perceptions towards digital games (for example: "What do you think about computer games?"), about their perceptions of digital learning games (for example: "Do you think that digital learning games have any added value over traditional instruction?"), whether in their opinion, it would be beneficial to replace traditional homework with digital learning games (for example: "What are your thoughts about replacing traditional homework with digital learning 
games?"), and what their opinion was regarding the contribution of digital learning games to their children's achievements (for example: "Do you think that homework with digital learning games can enhance children's achievements?”).

Approximately half of the interviews were performed face-to-face and due to logistic circumstances, the remainder were performed by telephone. All the interviews were recorded with the interviewees' consent and transcribed in full, taking care to maintain the anonymity of the interviewees. Some of the interviewees were known to the researcher personally, and to some of them, she reached through mutual acquaintances.

The main themes that emerged from the interview analysis are skills that the children acquire during the use of digital games and digital learning games, the parents' perceptions of traditional homework, the manner in which technology is used in schools, parents' involvement in their children's homework preparation etc.

The questionnaire was filled by 198 parents, 142 mothers, and 52 fathers of students from all over Israel. Approximately half (51.3\%) were parents of elementary school students, and $48.7 \%$ were parents of junior and senior high school students. More than half of the parents $(51.8 \%)$ had their oldest child in the school, and they related to that in filling out the questionnaire.

In addition to the questionnaire, eight mothers and four fathers were interviewed. The ages of the interviewees ranged between 34 - 52. The researcher decided to stop interviewing after twelve interviews because the answers became repetitive and redundant.

\section{FINDINGS}

At the first stage of the data analysis the research variables were constructed. The variables that were examined included descriptive statistics and the internal reliability was tested according to Cronbach's alpha. The results of these tests appear in Table 1.

Table 1. Means, SD and internal reliability (according to Cronbach's $\alpha$ ), $\mathrm{N}=195$

\begin{tabular}{|c|c|c|c|}
\hline Questionnaire parts & $\mathbf{M}$ & SD & $\alpha$ \\
\hline Digital game & 3.24 & 0.71 & .81 \\
\hline Digital learning games & 3.61 & 0.77 & .83 \\
\hline Digital learning games as an alternative for traditional homework & 3.54 & 0.72 & .80 \\
\hline
\end{tabular}

Note: Possible range $=1-5 . a=$ Cronbach's alpha

\section{Answering Research Question 1}

To respond to the first research question, parents were asked about their views on the skills that their children acquired during their use of digital learning games, the results are presented in Table 2.

The data displayed in Table 2 clearly indicate that the parents see the skills that their children gain through use of digital learning games include: independent learning, curiosity, motivation and creative thinking. It appears that collaboration and responsibility and active involvement are seen as less significant in this context. The interviewees also related to skills that the children acquire when using digital learning games:

Children learn English, they learn to react quickly, to think quickly. The children learn to orient themselves in space, to occupy themselves, to share with others and to play together. ... children know how to attain almost all the information that they need (H., mother of children in Grades 4 and 6). 
Table 2. Means and SD for students' different skills acquired from digital learning games as perceived by parents, N=195

\begin{tabular}{|c|c|c|}
\hline Variable & M & SD \\
\hline Independent learning & 3.98 & 0.96 \\
\hline Curiosity, interest and motivation & 3.69 & 1.05 \\
\hline *Challenge and creative thinking & 3.63 & 1.21 \\
\hline *Collaboration & 3.41 & 1.16 \\
\hline responsibility and active involvement & 3.28 & 0.14 \\
\hline
\end{tabular}

* Items for which scales reversed

When children play with their friends they learn to wait for their turn, to respect rules, to listen and enjoy things together ... digital learning games can be excellent because they enable them to practice the materials before an exam, they can even invent games. Its preferable that if they play on the computer for so much time then they can also play games that involve learning, so they can master the materials, they can make mistakes and correct them and not be embarrassed, they can learn together and from each other (L., mother of children in Grades 2 and 5).

From these citations, it is evident that the interviewees also related to collaboration (although this skill was fourth in Table 2), but they also related to many other skills: improvement of English language skills, improvement of interpersonal communication, postponing satisfaction, respecting rules, digital literacy, orientation in space and fast thinking and reaction.

To respond to the first research questions the research also investigated parents' views on which skills are acquired by students during digital learning games employed as an alternative for traditional homework. The results appear in Table 3.

Table 3. Parents' perceptions towards digital learning games as an alternative for traditional homework, $\mathrm{N}=195$

\begin{tabular}{|c|c|c|}
\hline Variable & M & SD \\
\hline Meaningful learning and to construct knowledge & 3.88 & 1.18 \\
\hline Master learning materials (because of the immediate feedback) & 3.80 & 0.96 \\
\hline Motivation and learning from mistakes & 3.58 & 1.09 \\
\hline *Social interactions & & \\
\hline
\end{tabular}

${ }^{*}$ Items for which scale reversed

According to the parents' perceptions, the digital learning games used as an alternative for traditional homework enables students to enjoy meaningful learning and to construct knowledge, to master learning materials, to increase motivation and learn from their mistakes. It can also be seen that social interaction is seen as the least significant in this context.

The interviews revealed various views of the parents towards the use of digital learning games as an alternative for traditional homework. The more negative views are presented first and then the more positive views: 
I assume that the education system will not drag us into that madness ... I expect that whatever involves learning time in general and screen time will only occur in school (S., mother of children in Grades 1, 4 and 8).

I restrict the time that my children spend opposite the screen, I at least try hard to limit this but it doesn't always work, so I would not want school homework to add more screen time (G., mother of children in Grades 1 and 4).

The above citations indicate that the time that children spend opposite the screen, irrespective of whether it is for homework, is seen as a significant factor for the interviewees' negative views concerning digital learning games as an alternative for traditional homework. In contrast to these negative views, most of the parents expressed positive views, some of them also related to screen time, but in a completely different manner, as can be seen in the following citations:

I prefer him to play games which are learning games rather than simple computer games such as football, basketball or war games. If it's an activity that he can use to learn and gain value-added, then it's a blessing... I don't care about the screen time. Today it's a world that lives computers. More screen time, less screen time? On the contrary, let him invest his screen time in learning and not in rubbish ( $R$., father of a child in Grade 12).

It will finally be possible to solve this punishment of homework. Perhaps it will also be possible to excuse parents from the battles and policing concerning homework. I'm sure that many parents will be very happy for this to happen [for digital learning games to replace traditional homework]. The computer can definitely be an excellent tool and means to advance the child even without the parent and I am sure that many children will learn more than in the present form [of homework]. In my opinion there is no question here, the question is only when do we begin (G., mother of children in Grades 1 and 4).

These citations show that some of the interviewees claim that if their children are anyway sitting in front of a screen, it is preferable that they should enjoy learning activities. They also note that positive attitudes towards the use of digital learning games instead of traditional homework are connected to the characteristics of the game, such as challenge, enjoyment, content and complex graphics, and to the child's personal abilities such as motivation and independent learning. An additional interesting finding from these citations is the mention of tensions concerning homework. The interviewees believed that the use of digital learning games instead of traditional homework has the potential to reduce these tensions.

\section{Responding to Research Question 2}

To respond to the second research question, the difference was investigated between parents' attitudes towards digital games, digital learning games and digital learning games as an alternative for traditional homework, repeated measures ANOVA were performed for respondents.

The findings indicate that there is a significant difference between the attitudes of parents towards digital games, digital learning games and digital learning games instead of traditional homework $\left(f_{(2,388)}=57.57, p<.001\right)$. The size of the effect that was found was $22.9 \%$. In order to examine between which groups the difference exists, a Bonferroni test was performed. A significant difference was found between parents' attitudes concerning digital games $(\mathrm{M}=3.21, \mathrm{SD}=0.71)$ and parents' attitudes concerning digital learning games $(\mathrm{M}=3.58, \mathrm{SD}=0.79)$. Thus too, a significant difference was found between parents' attitudes concerning digital games and their attitudes concerning digital learning games as an alternative for homework $(\mathrm{M}=3.52, \mathrm{SD}=0.75)$. These findings indicate that the parents had more positive views concerning digital learning games and digital learning games as an alternative for homework than towards digital games in general. 
To answer this research question, tests were conducted to discover differences between parents' attitudes towards the research variables, with regard to children studying in elementary schools (Grades 1-3, 4-6) and with regard to children studying in junior and senior high schools (Grades 7-9, 10-12). To test these differences One-Way ANOVA tests were used. The findings show that there is no significant difference between the parents' attitudes towards digital games $\left(\mathrm{f}_{(3,328)}=2.106, \mathrm{p}>0.05\right)$, digital learning games $\left(\mathrm{f}_{(3,327)}=1.778, \mathrm{p}>0.05\right)$ and the use of digital learning games for homework $\left(f_{(3,327)}=1.647, p>0.05\right)$ among parents of children studying in elementary schools, and junior and senior high schools.

In contrast a significant different was found between the attitudes of parents towards the contribution of digital learning games to their children's achievements $\left(\mathrm{f}_{(3,324)}=2.809, \mathrm{p}<0.05\right)$. In order to investigate between which groups there was a significant difference, Bonferroni tests were conducted and it was found that the significant difference existed between parents with children in Grades 1-3 (Mean=3.16; $\mathrm{SD}=1.07$ ) and parents with children in Grades 4-6 (Mean=2.71; $\mathrm{SD}=1.05$ ). In other words, parents of children studying in the younger elementary school grades think that digital learning games serving as an alternative for traditional homework will contribute to their children's achievements more than parents of children studying in higher elementary school grades.

\section{Responding to Research Question 3}

To respond to the third research question, the research examined which factors predict the parents' attitudes concerning the use of digital learning games as an alternative for traditional homework. The quantitative data analysis showed that variables of attitudes towards technology, attitudes towards technological learning and the question "in your opinion, does the computer contribute to a sense of wellbeing" were found to have a strong correlation one with the other, so that it is possible that they together constitute one latent variable or factor.

Consequently, Confirmatory Factor Analysis was performed to test whether these three attitude variables were loaded on a single latent variable, which was dubbed "attitudes towards technology". Subsequently, this variable was tested to discover whether this variable could predict parents' attitudes towards the use of digital learning games as an alternative for traditional homework. The model also investigated whether parents' involvement in homework predicted attitudes towards the use of digital learning games as an alternative for traditional homework. It was decided to control the variables that might play an important role in the parents' attitudes towards the se of digital learning games as an alternative for homework: the students' grade (1=Grades 1-3; 2=Grades 4-6; 3=Grades 7-9 and $4=$ Grades 10-12), and whether there was an accessible computer for the child without limitations at home $(1=$ Yes; $2=$ No). The sex of the parent was also controlled ( $1=$ Male; $2=$ Female). The analysis found that the research model of the indices was a good fit:

$\chi 2(14)=25.50, p=.03, \mathrm{CFI}=.97, \mathrm{RMESA}=.07, \mathrm{SRMR}=.08, \mathrm{TLI}=.96$

As expected, it was found that the latent variable, attitudes towards technology ad towards learning through technology was explained by three attitude variables and positively and strongly predicted parents' attitudes towards the use of digital learning games as an alternative for traditional homework $(\mathrm{z}=13.83, \mathrm{p}<.001)$. Thus, insofar as the parent had more positive attitudes towards technology and its use for learning, then they would have more positive attitudes towards the use of digital learning games as an alternative for traditional homework.

Thus too, the variable: parents' involvement in homework preparation was found to be a positive and significant predictor in the model $\mathrm{z}=1.99, \mathrm{p}=.047$, so that insofar as the parent was more involved in their child's preparation of homework, then they would also have more positive attitudes towards the use of digital tools for the preparation of homework. It was also found that the learning stage predicted more positive attitudes towards the use of digital learning games as an alternative for 
traditional homework $(\mathrm{z}=1.98, \mathrm{p}=.048)$ so that parents of students in older stages-grades expressed more positive attitudes towards the use of digital learning games instead of traditional homework.

To summarize, it seems that attitudes towards technology and attitudes towards the use of technology in learning predict parents' attitudes towards the use of digital learning games instead of traditional homework. In addition, the students' learning stage and parents' involvement in preparation of homework also positively predict those attitudes. The summary of this model appears in Figure 1.

Figure 1. Research model (Continuous line = significant relationship; dotted line = non-significant relationship; the values are not standardized)

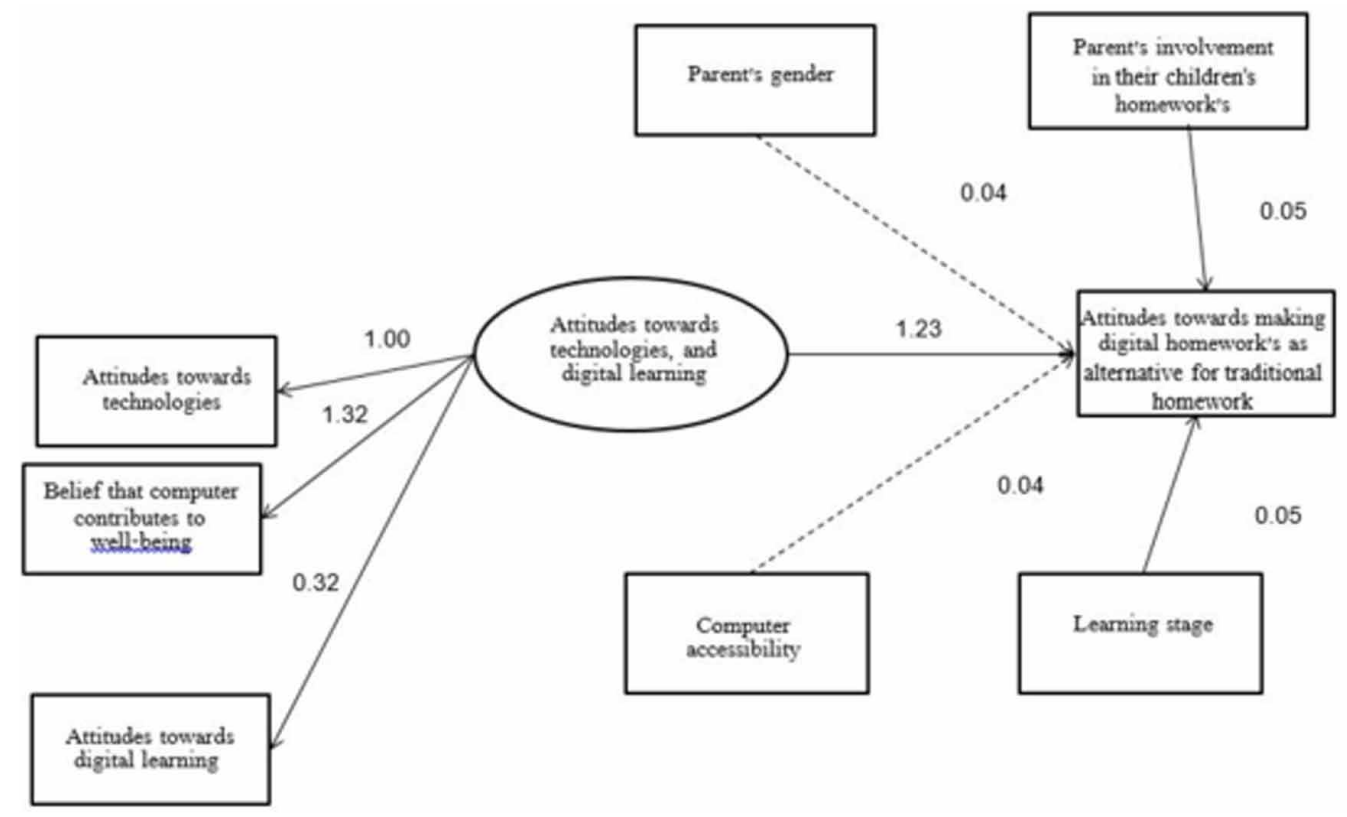

The qualitative data analysis revealed the interviewees' consideration of their children's homework, and enabled better comprehension of the reason for the positive correlation between parents' involvement in their children's homework and their attitudes towards the preparation of digital homework instead of traditional homework, as detailed in Figure 1.

Ten interviewees testified that they took an interest in their children's homework while two of them spoke about sitting with their children to prepare their homework:I follow the exams timetable, to see what they are studying. I don't go into their homework ...if there are specific things that she [her daughter] finds difficult or if she wants, I go over them with her (S., mother of children in Grades 6 and 9).The teacher sends us a message each day, telling us what they are learning and what lessons they need to do ... I checked it each time last year, and of course we sat together afterwards for another three hours ...before exams we would increase the strengths ...we would sit together, sometimes on Shabbat. We sat for several hours on each subject (B., mother of a girl in Grade 6).

These citations show that the parents report different levels of involvement in their children's homework, involvement that is characterized by support when the child asks for help and sometimes includes elements of supervision and control. It was interesting to see that when the interviewees were asked about their involvement in their children's lives, parents who testified that they sat with their children to prepare homework, only mentioned their involvement in learning, while parents who 
testified that they relied on the children to prepare their homework themselves spoke about more general involvement in their children's lives, relating to their involvement in homework preparation only when asked specifically about this. Another interesting finding relates to the difficult relationship between parents and children concerning homework preparation:Homework is a subject that is very sensitive in our home, it's difficult for our child to learn and we revolve around that a lot. There is a much tension ... I shout, am nervy, she cries, and then when she starts to cry she closes up and then she does not progress, Once she cannot progress and doesn't understand then I become even more annoyed and it ends with me getting up, and walking away to calm down and she cries (B., mother of a child in Grade 6).

The interviewees also related widely to their attitudes towards technology, most views were positive:I don't think that the computer is something negative. We lived in the streets, I don't know whether that was better ...computers and screen are a central part of our lives ... the computer is an excellent tool for life. Today it's possible to learn everything through the computer. If children know how to work on the computer, they will be more skilled, so I don't think children should be limited [in their computer use] (H., mother of children in Grades 4 and 6).I am not enthusiastic about those things. I am not sure that these computers, screen and labs will make the children any wiser. There is a lot of criticism about the use of computers ... and to tell the truth, I really don't like my children getting assignment from "Horizon" or "Waves" [the Ministry of Education online sites]... I have seen those assignments and it's the same as doing lessons in a notebook ... the same lady in different garb (S., mother of children in Grades 1, 4 and 8).

\section{DISCUSSION AND CONCLUSION}

One of the Ministry of Education's roles is to train students of the education system to integrate into the employment market. In recent decades, this role has become ever more challenging, since the education system needs to prepare the learners for an unknown and undefined reality, a world in which various new skills are needed (Barak, 2017). Education system graduates will need to integrate into an employment market, where the rapid development of sophisticated technology opens up many new channels of employment (Barak, 2017; Obschonka et al., 2017; Van Laar et al., 2017). One of the tools that can be identified as having the potential to assist such integration is the game (Romero et al., 2015). This is because many of the skills employed in the gaming process enable different learning and skills to be acquired.

The first research question examined the attitudes held by parents concerning the acquisition of skills through digital learning games and through the use of digital learning games instead of traditional homework. This was important to investigate because parents' attitudes towards these games and concerning rules for playing games at home, significantly influence the way in which their children perceive these games in the context of learning (Bourgonjon et al., 2011).

The findings show that parents believe that children participating in digital learning games acquire different skills during the games. The most prominent skill noted by the parents was independent learning. This skill enables the graduate to enjoy life-long learning (Romero 2015; Sourmelis et al., 2017). Other skills that parents noted included: curiosity, interest, motivation, coping with challenges, creative thinking, collaboration, digital literacy, improvement of interpersonal communication, respecting rules, improving English language skills, rapid thinking and reaction, taking responsibility and active involvement. These gaming skills that are acquired by children during use of the digital learning games and other digital games correlate with $21^{\text {st }}$ century skills, as defined by many scholars (Barak, 2017; Obschonka et al., 2017; Van Laar et al., 2017) and even add skills such as improvement the English language, improvement of interpersonal communication, postponing satisfaction, respecting rules, orientation in space etc. Thus, it seems that $21^{\text {st }}$ century skills can be acquired through digital learning games. 
The second research question examined the differences between parent's attitudes towards digital games, digital learning games and digital learning games as an alternative to traditional homework. The findings indicate that the parents had more positive attitudes about digital learning games and digital learning games as an alternative for homework than towards digital games in general. This is despite that the issue of whether to use digital learning games as an alternative for traditional homework is very complex. On the one hand, many students experience anger, boredom, anxiety and frustration during the preparation of homework (Moè et al., 2018). On the other hand, since there is a gap between the perception of the goals of homework - practice and revision of material learned in the classroom (Cooper et al., 2006; Moè et al., 2018) and the perception of a game - solely for entertainment and pleasure (Hamari et al., 2016). Digital learning games are not usually used for homework; the teachers' reticence to use them stems from the fear that this discrepancy in perceptions would lead parents to resist replacement of traditional homework with digital learning games.

The findings of this study indicate that in contrast to previous research (Piller \& Roberts-Woychesi, 2015) parents do not resist the replacement of traditional homework with digital learning games and even see this change as an opportunity for the acquisition of different skills such as meaningful learning and construction of knowledge, mastery of learning materials thanks to the immediate feedback that is obtained from the gaming process, learning from the mistakes and are increasing students' motivation. These findings also indicate that it is possible to develop $21^{\text {st }}$ century skills through digital learning games, even when they constitute an alternative for homework.

It can be noticed that there are two opposite spiral processes related to homework: One refers to traditional homework (negative process), and the other to digital learning games instead of traditional homework (positive process). In the negative spiral process, traditional homework is irrelevant to learners' lives, reduces their motivation to prepare them, and leads to arguments with their parents. The process repeated each time they receive homework of this kind, and their lack of motivation and arguments with their parents increase. In the positive spiral, the digital learning games, use as an alternative for traditional homework, which is relevant to learners' digital lives, increase their motivation to prepare them and reduce the arguments with their parents, and so forth.

The third research question examined the factors that influence parents' attitudes towards the use of digital learning games for homework. The research findings indicate that in addition to the positive attitudes towards the use of digital learning games instead of traditional homework, there are two more factors: Parents' involvement in their children's homework's, and the children's age.

Analysis of the interviews enabled the identification of two types of involvement in homework: parents who rely on their children to prepare their homework and provide support when asked to do so, and involvement characterized by supervision and control. Indeed, previous literature indicates that there are different types of parental involvement including parents' support for their children's autonomy, which involves positive trust for the child and emotional support, in contrast to parents' controlling behavior, characterized by pressure, intrusion and dominance (Moroni et al., 2015).

Not surprisingly, parents with controlling behavior about their children's homework, who reported tensions around homework preparation, introduce more positive attitudes towards digital learning games as an alternative for homework, probably to reduce the tensions about preparing them. The quantitative findings also indicate a correlation between parents' involvement in their children's homework and their attitudes towards digital homework as an alternative for traditional homework.

It was also found that parents of students who were in more advanced grades (junior and senior high school) expressed more positive views concerning the use of digital learning games instead of traditional homework than did parents of children studying in elementary schools. Perhaps this is because in recent years there have been many stories published concerning the success of young people that occurred before completing their studies (for example: Catherine Cook, Jon Wheatley, Fraser Doherty, Justin Bieber, part of 16 famous young and successful entrepreneurs who proved that age is nothing but a number), which could alter the way in which parents perceive "success", 
and show that it is possible to succeed by other paths than simply attaining high grades by (but not only) acquiring skills relevant for the contemporary and future world.

Given these findings, it is recommended that digital learning games be considered both for learning in schools and (even if occasionally) replacing traditional homework. It is recommended to create joint educational game meetings between teachers and parents and between teachers, parents, and students. Such meetings will expose all stakeholders to the benefits of educational games in the learning process, thereby easing their substitution in lieu of traditional homework. Furthermore, such meetings may increase parents' enjoyment levels during homework help and thus, even create a new source of quality time between parents and their children.

These findings are relevant not only in routine times but also in situations, when students cannot reach the different educational institutions and need to stay at home. In recent months, due to the COVID-19 pandemic, many students over the globe have been learning online. A serious burden has been imposed on parents, who are experiencing increased tension due to uncertainty concerning health and finances. In addition, students' lack of motivation, is augmented in times of emergency. In such situations, digital learning games can contribute positive educational activity for the students, and reduce unnecessary pressure for parents.

\section{Limitations}

The research sample was not large and relied on parental self-reporting. In addition, the research was conducted in Israel, known as the start-up nation. These factors may have had an effect on the positive attitudes of the parents, as presented in the study.

\section{Future Research Recommendations}

It is recommended to repeat this research on a large and varied population, considering the socioeconomic level and education level of the parents who participate. This is because these factors may from the beginning influence the parents' views concerning technology, consequently influencing the research findings and conclusions.

It is also recommended to conduct an experimental study, including two homogenous students' groups. One of the groups would continue to complete homework in a tradition way and the other will complete homework using digital educational games. Subsequently, it is recommended to interview both parents and students, and observe the parents 'involvement in their children homework's, the students' engagement to learning and the levels of the joy of learning in each of the groups. Moreover, it is noted that this study was conducted in Israel, a state in which most of the population has access to technology, to broaden knowledge on the research topic it is suggested to conduct research in states similar to Israel in levels of access to technology but also in states where there is less access to technology, a factor that could also influence research findings on the research topic. 


\section{REFERENCES}

An, Y. J., \& Cao, L. (2017). The effects of game design experience on teachers' attitudes and perceptions regarding the use of digital games in the classroom. TechTrends, 61(2), 162-170. doi:10.1007/s11528-016-0122-8

Anderson, T., \& Shattuck, J. (2012). Design-Based Research: A decade of progress in education research? Educational Researcher, 41(1), 16-25. doi:10.3102/0013189X11428813

Anero, N. (2019). Parental roles in educating the 21st century child towards the attainment of sustainable living. European Journal of Research and Reflection in Educational Sciences, 7(1).

Barak, M. (2017). Science teacher education in the twenty-first century: A pedagogical framework for technologyintegrated social constructivism. Research in Science Education, 2(47), 283-303. doi:10.1007/s11165-015-9501-y

Bellotti, F., Berta, R., De Gloria, A., \& Primavera, L. (2010). Supporting authors in the development of task-based learning in serious virtual worlds. British Journal of Educational Technology, 41(1), 86-107. doi:10.1111/j.14678535.2009.01039.x

Bempechat, J. (2019). The case for quality homework: Why it improves learning, and how parents can help. Education Next, 19(1), 36-44.

Binkley, M., Erstad, O., Herman, J., Raizen, S., Ripley, M., \& Rumble, M. (2010). Draft White Paper 1: Defining 21st Century Skills. http://cms. Education.gov.il/NR/rdonlyres/19B97225-84B1-4259-B4234698E1E8171A/115804/defining21stcenturyskills.pdf

Blau, I., \& Antonovsky, A. (2009). Teachers' openness to changes in professional and personal life. Unpublished work, Department of Education and Psychology, Open University of Israel. https://www.openu.ac.il/innovation/ chais2012/downloads/e-28.pdf

Bourgonjon, J., Valcke, M., Soetaert, R., De Wever, B., \& Schellens, T. (2011). Parental acceptance of digital game-based learning. Computers \& Education, 57(1), 1434-1444. doi:10.1016/j.compedu.2010.12.012

Buckley, P., \& Doyle, E. (2016). Gamification and student motivation. Interactive Learning Environments, 24(6), 1162-1175. doi:10.1080/10494820.2014.964263

Burriss, K. G., \& Snead, D. (2017). Middle school students' perceptions regarding the motivation and effectiveness of homework. School Community Journal, 27(2), 193-210.

Cai, J. (2003). Investigating parental roles in students' learning of mathematics from a cross-national perspective. Mathematics Education Research Journal, 15(2), 87-106. doi:10.1007/BF03217372

Carvalho, M. B., Bellotti, F., Berta, R., De Gloria, A., Sedano, C. I., Hauge, J. B., Hu, J., \& Rauterberg, M. (2015). An activity theory-based model for serious games analysis and conceptual design. Computers \& Education, 87, 166-181. doi:10.1016/j.compedu.2015.03.023

Ceka, A., \& Murati, R. (2016). The Role of Parents in the Education of Children. Journal of Education and Practice, 7(5), 61-64.

Central Bureau of Statistics. (2019). Annual Statistical Abstract. Chapter 17: Science, Technology and Communications, Selected Data. Jerusalem: CBS. [Hebrew]

Choy, D., Deng, F., Chai, C. S., Koh, H. L. J., \& Tsai, P. S. (2016). Singapore primary and secondary students' motivated approaches for learning: A validation study. Learning and Individual Differences, 45, 282-290. doi:10.1016/j.lindif.2015.11.019

Cooper, H., Robinson, J. C., \& Patall, E. A. (2006). Does homework improve academic achievement? A synthesis of research. 1987-2003. Review of Educational Research, 76(1), 1-62. doi:10.3102/00346543076001001

Denisova, A., \& Cairns, P. (2019). Player experience and deceptive expectations of difficulty adaptation in digital games. Entertainment Computing, 29, 56-68. doi:10.1016/j.entcom.2018.12.001

Donovan, L., Green, T. D., \& Mason, C. (2014). Examining the 21st century classroom: Developing an innovation configuration map. Journal of Educational Computing Research, 50(2), 161-178. doi:10.2190/EC.50.2.a 
Emes, C. E. (1997). Is mr pac man eating our children? A review of the effect of video games on children. Canadian Journal of Psychiatry, 42(4), 409-414. doi:10.1177/070674379704200408 PMID:9161766

Erhel, S., \& Jamet, E. (2013). Digital game-based learning: Impact of instructions and feedback on motivation and learning effectiveness. Computers \& Education, 67, 156-167. doi:10.1016/j.compedu.2013.02.019

Figueroa-Flores, J. F. (2016). Gamification and game-based learning: Two strategies for the 21st century learner. World Journal of Educational Research, 3(2), 507-522. doi:10.22158/wjer.v3n2p507

Fleming, T. M., Bavin, L., Stasiak, K., Hermansson-Webb, E., Merry, S. N., Cheek, C., \& Hetrick, S. (2017). Serious games and gamification for mental health: Current status and promising directions. Frontiers in Psychiatry, 7, 215. doi:10.3389/fpsyt.2016.00215 PMID:28119636

Fraiberg, S. (2017). Start-up nation: Studying transnational entrepreneurial practices in israel's start-up ecosystem. Journal of Business and Technical Communication, 31(3), 350-388. doi:10.1177/1050651917695541

Gao, F., Li, L., \& Sun, Y. (2020). A systematic review of mobile game-based learning in STEM education. Educational Technology Research and Development, 68(4), 1791-1827. doi:10.1007/s11423-020-09787-0

Goehle, G. (2013). Gamification and web-based homework. PRIMUS (Terre Haute, Ind.), 23(3), 234-246. do i:10.1080/10511970.2012.736451

Guillén-Nieto, V., \& Aleson-Carbonell, M. (2012). Serious games and learning effectiveness: The case of it's a deal! Computers \& Education, 58(1), 435-448. doi:10.1016/j.compedu.2011.07.015

Hamari, J., Shernoff, D. J., Rowe, E., Coller, B., Asbell-Clarke, J., \& Edwards, T. (2016). Challenging games help students learn: An empirical study on engagement, flow and immersion in game-based learning. Computers in Human Behavior, 54, 170-179. doi:10.1016/j.chb.2015.07.045

Hou, H. T., \& Li, M. C. (2014). Evaluating multiple aspects of a digital educational problem-solving-based adventure game. Computers in Human Behavior, 30, 29-38. doi:10.1016/j.chb.2013.07.052

Huang, B., Hew, K. F., \& Lo, C. K. (2018). Investigating the effects of gamification-enhanced flipped learning on undergraduate students' behavioral and cognitive engagement. Interactive Learning Environments, 27(8), 1106-1126. doi:10.1080/10494820.2018.1495653

Hung, C. Y., Sun, J. C. Y., \& Yu, P. T. (2015). The benefits of a challenge: Student motivation and flow experience in tablet-pc-game-based learning. Interactive Learning Environments, 23(2), 172-190. doi:10.1080/1049482 0.2014 .997248

Ibharim, L. F. M., Yatim, M. H. M., \& Zain, N. Z. M. (2019). Development of Rubric to Measure Children's 21 st Century Skills in Digital Game-Based Learning. Universal Journal of Educational Research, 7(10A), 7-12. doi:10.13189/ujer.2019.071702

Israeli Internet Association. (2015). What Do our Children Do with their Smartphones? [Hebrew] https://www. isoc.org.il/sts-data/11072

Iten, N., \& Petko, D. (2016). Learning with serious games: Is fun playing the game a predictor of learning success? British Journal of Educational Technology, 47(1), 151-163. doi:10.1111/bjet.12226

Katz, I., Kaplan, A., \& Buzukashvily, T. (2011). The role of parents' motivation in students' autonomous motivation for doing homework. Learning and Individual Differences, 21(4), 376-386. doi:10.1016/j.lindif.2011.04.001

Katz, I., Kaplan, A., \& Gueta, G. (2009). Students' Needs, teachers' support, and motivation for doing homework: A cross-sectional study. Journal of Experimental Education, 78(2), 246-267. doi:10.1080/00220970903292868

Kickmeier-Rust, M. D., \& Albert, D. (2012). Educationally adaptive: Balancing serious games. International Journal of Computer Science in Sport, 11(1).

Kingsley, T. L., \& Grabner-Hagen, M. M. (2015). Gamification: Questing to Integrate Content Knowledge, Literacy, and 21st-Century Learning. Journal of Adolescent \& Adult Literacy, 59(1), 51-61. doi:10.1002/jaal.426

Kiryakova, G., Angelova, N., \& Yordanova, L. (2014). Gamification in education. Proceedings of 9th International Balkan Education and Science Conference.

Kramer, W. (2000). What is a game, Really.http://www.thegamesjournal.com/articles/WhatIsaGame.shtml 
Moè, A., Katz, I., \& Alesi, M. (2018). Scaffolding for motivation by parents, and child homework motivations and emotions: Effects of a training programme. The British Journal of Educational Psychology, 88(2), 323-344. doi:10.1111/bjep.12216 PMID:29508390

Morgenshtern, O., Pinto, I., Vegerhof, A., Hoffman, T., \& Loutaty, S. (2018). Future-Oriented Pedagogy 2Future-2. Trends, Principles, Implications and Applications. Publications Division, Ministry of Education. https://meyda.education.gov.il/files/Nisuyim/eng_fop2summary.pdf

Moroni, S., Dumont, H., Trautwein, U., Niggli, A., \& Baeriswyl, F. (2015). The need to distinguish between quantity and quality in research on parental involvement: The example of parental help with homework. The Journal of Educational Research, 108(5), 417-431. doi:10.1080/00220671.2014.901283

Mtshali, T. I. (2020). Critical thinking skills for Civil Technology practical assessment tasks (PATs). World Transactions on Engineering and Technology Education, WIETE, 18(2), 237-241.

Obschonka, M., Hakkarainen, K., Lonka, K., \& Salmela-Aro, K. (2017). Entrepreneurship as a twenty-first century skill: Entrepreneurial alertness and intention in the transition to adulthood. Small Business Economics, 48(3), 487-501. doi:10.1007/s11187-016-9798-6

Palomino, P. T., Toda, A. M., Oliveira, W., Cristea, A. I., \& Isotani, S. (2019, July). Narrative for gamification in education: why should you care? In 2019 IEEE 19th International Conference on Advanced Learning Technologies (ICALT) (Vol. 2161, pp. 97-99). IEEE.doi:10.1109/ICALT.2019.00035

Perez-Liebana, D., \& Samothrakis, S. (2016, March). General video game ai: Competition, challenges and opportunities. Thirtieth AAAI Conference on Artificial Intelligence, 4335-4337.

Piller, Y., \& Roberts-Woychesin, J. (2015, May). Raising Parental Awareness about Game-based Learning. Conference on Computer Supported Education, 2, 385-389.

Qian, M., \& Clark, K. R. (2016). Game-based learning and 21st century skills: A review of recent research. Computers in Human Behavior, 63, 50-58. doi:10.1016/j.chb.2016.05.023

Rieber, L. P. (1996). Seriously considering play: Designing interactive learning environments based on the blending of microworlds, simulations, and games. Educational Technology Research and Development, 44(2), 43-58. doi:10.1007/BF02300540

Romero, M. (2015). Work, games and lifelong learning in the 21st century. Procedia: Social and Behavioral Sciences, 174, 115-121.

Romero, Usart, \& Ott. (2015). Can serious games contribute to developing and sustaining 21st century skills? Games and Culture, 10(2), 148-177. doi:10.1177/1555412014548919

Rosseel, Y. (2012). Lavaan: An R Package for Structural equation modeling and more. Version 0.5-12 (BETA). Journal of Statistical Software, 48(2), 1-36. doi:10.18637/jss.v048.i02

Sardone, N. B., \& Devlin-Scherer, R. (2010). Teacher candidate responses to digital games: 21st-century skills development. Journal of Research on Technology in Education, 4(24), 409-425. doi:10.1080/15391523.2010 .10782558

Schöbel, S. M., Janson, A., \& Söllner, M. (2020). Capturing the complexity of gamification elements: A holistic approach for analysing existing and deriving novel gamification designs. European Journal of Information Systems, 1-28.

Sharp, L. A. (2012). Stealth learning: Unexpected learning opportunities through games. Journal of Institutional Research, 1, 42-48. doi:10.9743/JIR.2013.6

Soulé, H., \& Warrick, T. (2015). Defining 21st century readiness for all students: What we know and how to get there. Psychology of Aesthetics, Creativity, and the Arts, 9(2), 178-186. doi:10.1037/aca0000017

Sourmelis, T., Ioannou, A., \& Zaphiris, P. (2017). Massively multiplayer online role-playing games mmorpgs and the 21st century skills: A comprehensive research review from 2010 to 2016. Computers in Human Behavior, 67, 41-48. doi:10.1016/j.chb.2016.10.020 
Sung, H. Y., Hwang, G. J., Wu, P. H., \& Lin, D. Q. (2018). Facilitating deep-strategy behaviors and positive learning performances in science inquiry activities with a $3 \mathrm{~d}$ experiential gaming approach. Interactive Learning Environments, 26(8), 1053-1073. doi:10.1080/10494820.2018.1437049

Sweetser, P., \& Wyeth, P. (2005). GameFlow: A model for evaluating player enjoyment in games. Computers in Entertainment, 3(3), 3-3. doi:10.1145/1077246.1077253

Van Laar, E., van Deursen, A. J., van Dijk, J. A., \& de Haan, J. (2017). The Relation between 21st-Century skills and digital skills: A systematic literature review. Computers in Human Behavior, 72, 577-588. doi:10.1016/j. chb.2017.03.010

Wang, Y. H. (2019). Exploring the effectiveness of adopting anchor-based game learning materials to support flipped classroom activities for senior high school students. Interactive Learning Environments, 1-20. doi:10. $1080 / 10494820.2019 .1579238$

Xu, F., Buhalis, D., \& Weber, J. (2017). Serious games and the gamification of tourism. Tourism Management, 60, 244-256. doi:10.1016/j.tourman.2016.11.020

Yildirim, I. (2017). The effects of gamification-based teaching practices on student achievement and students' attitudes toward lessons. The Internet and Higher Education, 33, 86-92. doi:10.1016/j.iheduc.2017.02.002

Zahra, J., Fatemeh, J., Mohammad, S., \& Maryam, B. (2017). Relationship between designing computer-based educational games, and learning motivation among elementary students. International Journal of Pediatrics, 5(12), 6231-6244. 